\title{
Cómo se traza una vida. Notas sobre Ikebana política de Claudia del Río*
}

Fecha de recepción: 8 de febrero de 2018

Fecha de aprobación: 15 de mayo de 2018

\section{Resumen}

En este trabajo ensayamos una lectura crítica de Ikebana política, la edición en libro de algunos fragmentos tomados de los diarios y cuadernos personales de la artista plástica argentina Claudia del Río ${ }^{1}$, centrándonos en dos tópicos: a. las similitudes éticas y estéticas entre la composición de libros rapsódicos, a través de la técnica del collage, y el montaje de una muestra de dibujos; y b. los modos en que la edición de papeles personales responde al imperativo moderno de convertir la propia vida en obra de arte, a través del recurso a la fragmentación y la dispersión de los rasgos egotistas. Se exploran además los alcances éticos de las escrituras de sí mismo cuando se las lee como ejercicios espirituales y el vínculo entre la pulsión archivística que mueve la composición de Ikebana política y los procesos de autofiguración de la autora como artista y docente autodidacta.

Palabras clave: Claudia del Río; Ikebana política; arte y vida; escritura de sí mismo; ejercicio espiritual.

$1 \quad$ Claudia del Río nació en Rosario (Argentina), en 1957. Es artista plástica y docente universitaria. En los 80 integró en grupo APA (Artistas Plásticos Asociados). En los 90 fue parte del Programa de Clínica de Obra a cargo de Guillermo Kuitca. En 2002 cofundó con Mario Germín el Club del Dibujo, un espacio de pensamiento y acción acerca del dibujo. Desde 2006 coordina el proyecto Pieza Pizarrón, un dispositivo itinerante de arte, teatro y pedagogía. Sus obras se encuentran en colecciones públicas y privadas, museos e instituciones de Argentina, Brasil, Canadá, Cuba, Ecuador, España, Estados Unidos y Francia. Publicó el poemario Litoral y Cocacola (2012) y Pieza Pizarrón (2013).

Citar: Giordano, A. (enero-junio de 2018). Cómo se traza una vida. Notas sobre Ikebana política de Claudia de Río. La Palabra, (32), 129-138. doi. org/10.19053/01218530.n32.2018.8167.

\begin{abstract}
Alberto Giordano
Nació en Rufino en 1959; vive en Rosario desde 1971. Es crítico y ensayista. Dicta clases de teoría literaria en la Universidad Nacional de Rosario. Como investigador de CONICET, se ocupa de las llamadas "escrituras del yo" y de los modos del ensayo literario. Entre sus libros se encuentran: Manuel Puig, la conversación infinita (2001), Modos del ensayo. De Borges a Piglia (2005), Una posibilidad de vida. Escrituras intimas (2007), El giro autobiográfico de la literatura argentina actual (2009), La contraseña de los solitarios. Diarios de escritores (2013), El pensamiento de la crítica (2015) y El tiempo de la convalecencia. Fragmentos de dun diario en Facebook (2017). albertogiordano59@gmail.com
\end{abstract}

* Artículo de reflexión. 


\title{
la palabra
}

\section{Tracing Life. Notes on Ikebana política [Political Ikebana] by Claudia del Río}

\begin{abstract}
This paper attempts a critical reading of Ikebana politica, the book edition of a series of fragments extracted from the diaries and personal notebooks of the Argentinian artist Claudia del Río. We focus on two topics: a) ethical and aesthetic similarities between the composition of rhapsodic books using the collage technique and the montage of a drawing exhibition, and b) the ways in which the publication of personal writing responds -through the fragmentation and dispersion of egotistical traits- to the modern imperative of transforming one's life into a work of art. This paper also explores the ethical scope of self writing when read as a series of spiritual exercises, as well as the relation between the archival impulse pushes forth the composition of Ikebana politica, and the self figuration of the author as artist and selftaught teacher.
\end{abstract}

Keywords: Claudia del Río; Ikebana Política; Life and art; Self writing; Spiritual exercises.

\section{Comment on trace une vie. Ébauche sur Ikebana politica [Ikebana politique] de Claudia del Río}

\section{Résumé}

Dans cet article, nous proposons une lecture critique d' Ikebana politique le livre composé de fragments tirés des journaux intimes et des carnets personnels de l'artiste argentine Claudia del Río. Nous nous pencherons sur deux sujets: a. les similitudes éthiques et esthétiques entre la composition des livres rhapsodiques à travers la technique du collage et l'assemblage d'un échantillon de dessins; $b$. la manière dont l'édition de documents personnels répond à l'impératif moderne de transformer sa vie en œuvre d'art, en utilisant la fragmentation et la dispersion de caractéristiques égotistes. Nous étudierons la portée ethique des écrits du moi lorsqu'ils sont lus comme des exercices spirituels. Nous analyserons le lien entre l'élan archivistique qui configure la composition d'Ikebana politique et les processus d'autofiguration de l'auteur en tant qu'artiste et enseignant autodidacte.

Mots-clés: Claudia del Río; Ikebana politique; l’art et la vie; écriture du moi, exercice spirituel. 
"Dibujar como se vive, vivir como se dibuja. No sé."

Claudia del Río, Ikebana política

El 25 de noviembre de 2013, Claudia del Río anota en uno de sus cuadernos personales, que estuvo leyendo los diarios de Katherine Mansfield y cita un fragmento, para celebrar la plasticidad del estilo, la ligereza con la que Mansfield desgrana las ideas que despuntan en cada jornada, cómo "Interrumpe y retoma" (del Río, 2016, p. 198). ${ }^{2}$ La escritura de una vida, el movimiento que pasa a través de las palabras para que el registro no inmovilice ni sature de sentido el encadenamiento de las vivencias, es esencialmente una cuestión de ritmo. Del Río lo nota en los diarios de Mansfield porque tal vez lo aprendió antes en sus propios ejercicios intimistas.

Al presentar la vida como un proceso in medias res, pautado por la dinámica de la interrupción y el recomienzo (la insistencia de lo que no tiene causa ni fin), la forma discontinua del diario es la que produce el efecto de autenticidad biográfica más potente y una perdurable sensación de realidad. De allí la fuerza con la que puede conmovernos, aunque (¿sobre todo cuando?) los apuntes rozan lo insignificante. Desde el punto de vista de lo que revela la escritura del diario, la vida tiene que ver menos con el desarrollo de una historia personal, que, con un proceso, o devenir, íntimamente extraño ${ }^{3}$. Algo que Virginia Woolf registró con sobriedad y precisión, al referirse a las oscilaciones anímicas como movimientos aleatorios de "pleamar y bajamar", o como el misterioso ir y venir de la niebla (Woolf, 1954, p. 24).

La vida sería un acontecimiento impersonal que se define por lo que puede, por la plasticidad de lo viviente para recrearse a través de la multiplicación de sus conexiones, según la alternancia entre movimientos heterogéneos (expansión/contracción, insistencia/desvío). En otro apunte de 2013, algún día de julio, del Río se detiene en el carácter esquivo de lo que llamamos "ritmo", para responder a las inquietudes de un interlocutor innominado, $\mathrm{y}$ reflexiona, a su manera, por tanteos y encadenamiento de impresiones, sobre la función constructiva de los efectos rít- micos en el diseño de las obras artísticas. Dice que es algo que comprendió gracias a la lectura de sus poemas en voz alta $^{4}$ el ritmo sería como un esqueleto que sostiene la carne, se oculta o no se da inmediatamente, pero igual podemos percibirlo, si el oído atiende a las pulsaciones de lo íntimo, eso que el discurso no puede pero querría decir. "Entonces ten contigo al ritmo como una medida amable" (p. 191), aconseja, como si dijese: considéralo una pauta afectiva de la que dependería la eficacia estética de las obras, la fuerza con la que nos conmueven.

El 2013 es el año en el que del Río lee con admiración los diarios de Katherine Mansfield, reflexiona sobre la importancia estética del ritmo y vive una segunda infancia en compañía de poetas; es también el año en que se decide a componer un libro rapsódico, con fragmentos extraídos de los 89 cuadernos-libretas en los que vino llevando, desde hace tiempo, diarios personales y de artista; el año en el que se le habrán planteado, entonces, los problemas propios de la composición de libros

\footnotetext{
En lo que sigue, los números entre paréntesis sin indicación de autor remiten, en todos los casos, a del Río (2016). Hernández (2016) y González (2017) profundizan en las posibilidades y alcances del diario como género literario. A su vez, Souza (2017) y Surghi (2017) reflexionan sobre las complejidades de la relación entre escritura autobiográfica y vida.

4 En otra entrada del mismo año, la del 3 de diciembre, agradece a esta práctica la posibilidad de estar viviendo "una segunda infancia en el arte" (p. 199). Leer poesía en voz alta, entre poetas (clínicas o presentaciones), supone otros modos de poner en juego la inarticulación entre cuerpo y lenguaje, y propicia nuevas formas de sociabilidad. La experiencia del recomienzo (¿hay alguna más dichosa?), del retorno a la condición exigente y venturosa del aprendiz, es un horizonte hacia el que tienden todos los gestos estéticos que realiza del Río, cualquiera sea la naturaleza de su performance.
} 
rapsódicos: ¿según qué pautas resolver la selección y el encadenamiento de los fragmentos, atendiendo a la heterogeneidad de los materiales y al deseo de que el valor documental no debilite la manifestación de los ritmos vitales?, ¿cómo dotar al libro de la plasticidad suficiente para que el acabado retórico no borre las huellas de la inestabilidad en la que transcurrieron los ejercicios que están en su origen? Se podría decir que son problemas similares a los que se le plantearán a la dibujante cada vez que monta una muestra en una galería o un museo: ¿cómo preservar la potencia paradójica de lo frágil, del acto de trazar antes de que lo inmovilice el adjetivo, en las condiciones que impone un espectáculo con pretensiones de legitimidad cultural? ${ }^{5}$

Ikebana politica es una respuesta en acto a los problemas que plantea la composición de libros rapsódicos: el uso intensivo de la técnica del collage, el encadenamiento sin mediaciones de fragmentos heterogéneos, que remiten a una multiplicidad proliferante de series temáticas y formales (en una lectura apresurada, se pueden identificar más de veinte); al mismo tiempo que produce el agrupa- miento, deja el conjunto en un estado de desagregación virtual, como si pudiera descomponerse desde dentro, menos por la localización de una falla, que por la exacerbación de alguna singularidad. La unidad del libro es un efecto de la insistencia de lo múltiple, de la resonancia de $\mathrm{y}$ entre las diferencias temáticas y estilísticas de cada serie. Unidad paradójica que remite a los estilos de vida de la escritora-montajista, al deseo de no dejar de investigar(se), y solo en una segunda instancia a previsiones retóricas. Siempre que se escribe para responder a las necesidades de la vida, la necesidad que tiene lo viviente de no dejar de ser y de expresarse, los problemas compositivos se formulan desde un punto de vista ético. De allí, la definición de "collage" que ensaya del Río en otra digresión "metodológica" de su diario: "El collage [es] el arte del contacto, la fórmula del estar juntos entre diferentes" (p. 205).

De igual manera, 2013 es el año en el que comienzan los trabajos de edición de Ikebana politica, pero el impulso de revisar los 89 cuadernos y libretas, para observar qué huellas fue dejando una vida de artista en sus páginas, viene de un poco antes.
"Vigo decía que después de los cincuenta toca archivo. Enero y febrero haré eso. El plan es revisar cada cajón, caja, mueble" (p. 153).

El 5 de enero de 2011, a sus 53 años, del Río vuelve a elegir a Edgardo Vigo como maestro espiritual y se convierte en archivista de sí misma. El despertar de la pulsión de archivo y la convicción, más que la conciencia, de la propia finitud, son dos fenómenos que se presuponen e iluminan mutuamente. Sándor Márai (2008) anotó en sus diarios de vejez, que "La proximidad de la muerte confiere a la conciencia más fuerza que desánimo" (p. 33). La intimidad con el sinsentido de la muerte daría a la vida un sentido más intenso que el del transcurrir sin conciencia de la radical indeterminación. Algo de esta circunstancia existencial paradójica simpatiza con la orientación doble del trabajo archivístico, que conserva el pasado, pero también lo recrea, incluso lo inventa, para que se lo pueda revivir como nunca ocurrió.

Ikebana política es el "archivo sentimental" de una vida de artista y una obra de madurez, un dispositivo para la recreación de sí mismo a una edad en la que el

\footnotetext{
5 "No adjetivo mientras trabajo" -anota del Río en una entrada de 2005. "Entrenar es pasar del adjetivo al acto, eso es entrenamiento en dibujo. Asumamos riesgos, seamos honestos, exageremos e inventémonos algo. Y siempre investiguemos" (p. 48). El riesgo mayor al que se exponen quienes consiguen suspender la sanción que portan los adjetivos, los que experimentan la afirmación en bruto, sin pretensiones, del goce de trazar, es el enrarecimiento o la casi extenuación de la identidad profesional. "Dibujante es quien dibuja" (p. 29), le gusta repetir a del Río, para desprender el acto de una valoración institucional (dibujante es el que dibuja bien, el que sabe dibujar en general) y señalar lo provisorio y evanescente de sus efectos (dibujante es quien dibuja cada vez, en el intervalo que se abre entre las certidumbres de ser y no ser dibujante).
} 
horizonte de la finitud puede resultar un estímulo y no solo una amenaza. Por eso, no es raro que se abra con un gesto más propio del relato autobiográfico y su inclinación retrospectiva, que del registro diarístico: la narración de un recuerdo de infancia con valor de escena primitiva, en el que podría sostenerse un proceso de "autofiguración". Todas las mañanas, mientras la hermana mayor asistía a la escuela, Claudia jugaba a la escuela en la cocina, debajo de una gran mesa de madera. "Tenía un delantal rosa a cuadritos y un portafolio, adentro manguines, cuadernos, lápices, un vaso de plástico plegado" (p. 15). Jugaba a dibujar bolas de Navidad, un juego exigente, porque trazar círculos, conseguir que las dos direcciones se encontraran, era una hazaña. Cuando la mayor volvía, la menor regresaba a la superficie de la vida familiar. Con el olvido de su lado, la memoria adulta recuerda con precisión alegórica: a los mayores los instruyen las instituciones escolares; los menores pueden aprender de sí mismos lo esencial mientras juegan: a estar solos, a orientar los aprendizajes en la dirección incierta de lo que se querría ser. Sobre este paralelismo se construye la imagen del autodidacta, con la que del Río quiere que la identifiquemos como artista y docente, una imagen que envuelve la afirmación soberana de que la investigación y la creación no dependen del virtuosismo demostrable, sino del ejercicio obcecado de un saber hacer sin compromisos con el Saber instituido.

La práctica y la promoción del autodidactismo son motivos recurrentes en las entradas de Ikebana política, junto con la idea de que es necesario conquistar metódicamente un estado de inocencia, como el del niño que se ocupa de dibujar y no le importa si sabe o no hacerlo, para sobrevivir activamente a las intimidaciones de la especialización. "Aliento el autodidactismo como el lugar donde se puede construir un plan. $\mathrm{O}$ una suma de planes bien cortos, divergentes, arborescentes o no. Planes cortos, que puedas cumplir [...]" (p. 24). "El autodidactismo nunca te dejará a pie" (p. 99). Lo mismo cuando se escribe que cuando se dibuja, si el trazo improvisa la marcha y la interroga evitando la fijeza de la reflexión, el autodidactismo es menos una posición minoritaria, la asunción autosatisfecha de una marginalidad previsible, que un programa para la ejercitación sutil y desinteresada de la "propia" rareza a través del desplazamiento y la interrupción. "Dibujante es quien dibuja", y autodidacta, quien improvisa a solas, en una soledad radical, porque, se podría decir, para que la improvisación ocurra, ni siquiera él -lo que ya sabe de sí mismo con certeza- debe estar presente.

Siempre atractiva y polémica en cualquiera de sus formulaciones, la imagen del autodidacta se vuelve encantadora en Ikebana política, porque transmite orgullo, pero no resentimiento ni arrogancia, esas pasiones tristes que suelen ganar a los intelectuales cimarrones cuando recelan por la falta de reconocimiento y legitimación. Porque artista, del Río se quiere "intelectual silvestre" (p. 228) y descuenta, con ánimo juguetón y pose ligeramente provocadora, que la publicación de sus cuadernos "contribuirá aún más al rumor de que los artistas somos bien tontos" (p. 35). Un modo certero de desplazarse fuera de las disputas por la legitimidad cultural, usufructuando de la potencia desestabilizadora de cierta -imprescindible- frivolidad.

Al rencontrarse con sus dibujos de infancia, las bolas de Navidad, la archivista recuerda inmediatamente el gusto que sintió al trazarlos, el cuerpo revive la alegría de la proeza cumplida, mientras la imaginación

$6 \quad$ Sobre el recuerdo de infancia como escena arcaica que funda el acto autobiográfico, ver Rosa (1990, 59-65). El concepto de "autofiguración" lo tomamos en el sentido que le da Molloy (1996). Al rememorar sus vidas desde la perspectiva de un sujeto que busca apropiarse del pasado para ganar consistencia e interés, los escritores figuran imágenes de sí mismos por las que esperan ser reconocidos y valorados. 
descubre inclinaciones afectivas que el gesto autobiográfico convertirá en originarias. "Esos dibujos tienen una gran concentración. Son apretados, vienen de una caída, hay cierto ensimismamiento en ellos" ( $p$. 15). Se podría especular sobre el interés de del Río por fundar "instituciones de autor", "clubes" en los que las políticas de la institución simpaticen con las de la amistad, derivándolo de aquella experiencia infantil del ensimismamiento laborioso. Las "protoinstituciones" -las únicas capaces de preservar el deseo de investigación que llevó a fundarlas- se proponen como espacios de experimentación y encuentro entre singularidades, para que cada cual pueda ejercitarse en lo que tiene de diferente. Son un remedio circunstancial para los peligros del ensimismamiento (la objetivación narcisista) y un recurso para la preservación de la soledad como condición de cualquier acto creativo. Por eso son instituciones frágiles, vulnerables, por lo mismo que las hace potentes: la disposición a desaparecer apenas comienza a obstruir el paso de la vida a través de las prácticas y los rituales.

Ikebana política documenta este interés de del Río por las instituciones que saben cortejar su ruina, en las entradas del pri- mer y del último año (aunque la suponemos casual, la simetría juega con la idea de "preocupación constante"). En las del 2005, referencias al Club del Dibujo, el experimento más logrado, en términos de visibilidad, duración y efectos micropolíticos $^{7}$; en las del 2015 , fantasías sobre una improbable "Escuela de Arte Pública Soñada" (p. 227), la clase de institución que se consuma y extingue en el acto de imaginarla (su valor es relativo al placer de proyectarla sabiéndola irrealizable, y a la fuerza con que la postulación de lo irreal sacude el manto reactivo que envuelve las propuestas de institucionalización convencionales).

La ética y los humores del autodidacta también perfilan la figura del profesor apasionadamente escéptico, "siempre en crisis con lo enseñable” (p. 61), un profesor que duda, mientras insiste en enseñar algo, si realmente hay algo para enseñar o si es posible enseñar lo que realmente valdría la pena aprender: cómo perseverar creativamente en la exploración de la propia rareza. Las entradas de Ikebana política recogen e interrogan las vivencias de del Río como profesora de dibujo en contextos académicos (los más resistentes al ejercicio del autodidactismo) y en las llamadas "clínicas" para artistas jóvenes. ¿Qué pue- de enseñar un profesor de dibujo que aprendió, en el ejercicio desestabilizador de su arte, que es necesario mantener a raya las arrogancias del saber para investigarse en serio, sin temor a extraviarse o a no concluir? ¿Se puede enseñar a contar con la fragilidad como recurso y no solo como obstáculo? ¿Se puede enseñar a no administrarse, incluso a perder desinteresadamente?

Lo dichoso - esa dicha despunta a cada paso mientras leemos Ikebana política, como lo hará seguramente en las clases que dicta del Río- es que cuanto más radical se vuelve la duda, más se fortalece la convicción de que vale la pena insistir. Hay vitalidad, incluso alegría, en esos estados de crisis. En verdad, ningún profesor que se sitúe desde el punto de vista de la experiencia sabe bien qué pueden aprender sus jóvenes estudiantes, porque a él solo le toca enseñar. Aprenden los otros, según lo que pueden, quieren o no pueden evitar querer (extremando el argumento, se podría arriesgar que los aprendizajes auténticos, los transformadores, siempre los realizan otros, incluso si se los piensa desde el punto de vista del aprendiz: el sujeto del aprendizaje presupone algo que el estudiante desconoce de sí mismo, una otredad de afectos y posibilidades téc-

$7 \quad$ Los fundamentos que llevaron a la creación del Club del Dibujo, más algunos intercambios y algunas performances que propició su existencia, están expuestos en: http://clubdeldibujo.com/ (última visita: 3 de junio de 2017). 
nicas a la que solo podrá acceder cuando se haya cumplido la transformación).

Como juega, con irónica seriedad, a ser un libro de autoayuda para artistas y docentes, Ikebana política propone un camino para la explotación pedagógica de la crisis: que el profesor se deslice imperceptiblemente hacia la condición del aprendiz mientras enseña. "Estoy interesada en que los estudiantes me den problemas. Ese es mi trabajo" (p. 75). La clase habrá sido ocasión de aprendizaje, si el profesor supo convertir las inquietudes de sus estudiantes en gestos magistrales ("la función del maestro" -dice Rancière (2014, p. 76)- "es ser quien propone una pregunta que se nos viene encima y ante la cual hay que reaccionar"). Ninguna demagogia en esta salida, porque los estudiantes nunca sabrán del rol paradójico que les tocó jugar en la clase, no podrían saberlo, interesados como están en articular problemas para tratar de aprender.

(La autodidacta aprende de sí misma poniéndose a prueba en soledad, pero los encuentros con otros artistas son fundamentales para sus aprendizajes: los estimulan, los inspiran, les dan ocasión de interrogarse. Ikebana política registra la presencia de varios maestros circunstanciales en la vida de del Río: Guillermo Kuitca, Rubén de la Colina, Edgardo Vigo y el inefable Delfo Locatelli, entre otros. Cada uno realizó el gesto conveniente en un momento preciso, a veces sin propósito pedagógico, nada más por dibujar un paisaje misterioso con sus actos o sus obras. Las entradas que los evocan o los añoran transmiten una calidad específica de agradecimiento, el que también celebra la generosidad de haber podido recibir. Un día de enero de 2008, del Río visita en su casa a Mele Bruniard, recientemente accidentada. Conversan y revisan cuadernos de dibujo y escritura. "Quedé pletórica, me transmitió una enorme voluntad y el punto de cuánto cree una en una misma" (p. 112).

La ética del arte moderno se formularía, según un transitado texto de Nicolás Bourriaud (2009), en el imperativo "haz de tu vida una obra de arte" (p. 16). Convertir la vida en obra supone, por una parte, la decisión de montar un espectáculo, el de la singularidad del artista como viviente anómalo; y, por otra, el deseo de realizar una experiencia, la de la naturaleza insustancial y proteica de la subjetividad. La idea de que las obras deben proponerse como dispositivos de existencia, rinde tributo al egotismo de los artistas modernos, pero también a su disposición para experimentar con lo desconocido de sí mismos, para explorar posibilidades de existencia inauditas. Cuando del Río toma apuntes de su vida, la fragmenta y la dispersa, según la pauta del diario y un arte de la notación sutil, al mismo tiempo que alimenta el ego lo restringe, para que la escritura de sí misma no pierda vigor, pero tampoco plasticidad ni impulso exploratorio. "Cuando el ego es poco, es un fieltro que amortiza las caídas, me hace sonreír y volver a empezar" (p. 69). Hay un ligero extrañamiento en esta notación que conviene señalar porque expresa todo lo que puede el estilo intimista de del Río: bajo la máscara de un yo reflexivo, el sujeto de la enunciación es el cuerpo que investiga, el que se contrae o se expande, se inhibe o se potencia, según lo que le salió al paso. Es el cuerpo que dibuja o escribe antes de que los adjetivos sancionen la calidad del trazo, el que interrumpe y retoma porque sí (sin esa intransitividad primera no podría haber verdadera investigación de sí mismo).

Una lista incompleta de lo mucho y diverso que registran las entradas de Ikebana política: poemas, reflexiones, notas de lectura, diálogos imaginarios, ocurrencias (suelen tomar la forma de máximas o "slogans"), listas (de nombres de barcos que pasan, de las veces que la poeta leyó en vivo, de los cuadros de una muestra), apuntes para una conferencia, el recuerdo de algunos encuentros o de visitas a otros artistas, proyectos, descripciones de paisajes, 
transcripciones de documentos, plegarias, propósitos para el año que comienza, intercambios por inbox en Facebook, un cuestionario con 133 preguntas dirigido a artistas jóvenes, un discurso funerario en ocasión de la muerte de León Ferrari, registros de lo trivial (para el insomnio, la diarista toma Rivotril) y de lo absolutamente extraordinario (la muerte del padre), vivencias de los viajes con propósitos artísticos (residencias $\mathrm{y}$ clínicas) y, como en un juego de cajas chinas, la transcripción completa del "Diario de Bispo, Río de Janeiro" (casi veinte páginas con el registro encantado de lo que ocurrió durante una residencia artística en un hospital psiquiátrico abierto $)^{8}$. Cada apunte añade un matiz al autorretrato, o refuerza discretamente un trazo anterior, y lo que va apareciendo, inestable, no es un carácter sino una sensibilidad.

La fragmentación de las secuencias y la dispersión de los rasgos, reducen el ego a un polo de atracciones y rechazos circunstanciales. Una entrada de 2007, diagrama la composición heteróclita de la subjetividad artística a través de una lista, seguramente provisoria, de veinticuatro relaciones (con el mercado, con el cuerpo, con los pares, con el tiempo, con la idea de profesionalidad, con el archivo, con la muerte...). La identidad como un haz de múltiples remisiones.

Los experimentos de artistas contemporáneos que apuestan a la transformación de la vida en obra se piensan como ensayos, en el sentido de tentativas circunstanciales y efímeras. Bourriaud (2009) identifica una impronta oriental en la valoración de lo frágil y lo fugaz, ajena al "deseo occidental de monumentalidad" (p. 89). Con gesto irónico, porque se trata de un libro -y el libro tiene siempre algo de monumental, aunque esté compuesto como una reflexión sobre el paso del tiempo-, Ikebana política rubrica la impronta budista desde el título. La ikebana es un arte japonés del arreglo floral fundado en la observación de las formas y las fases del crecimiento natural. Sus principios son la economía de recursos y el ascetismo de las formas. Como es un ejercicio espiritual antes que una práctica estética, el efecto decorativo resulta secundario, algo que se da por añadidura, y lo que realmente importa, como en el dibujo según del Río9, son las condiciones en las que se realiza el acto de compo- ner el arreglo: la concentración $\mathrm{y}$ el silencio, que interrumpen la logorrea, y la observancia de ciertas restricciones. Entre quienes promueven su práctica, toda ikebana sería política, un camino para llegar a ser más paciente y tolerante con las diferencias, porque exige cuidar de los matices ${ }^{10}$.

La vía de la espiritualidad, en el sentido foucaultiano de los ejercicios que el sujeto realiza sobre sí mismo con miras a una transformación que le permitiría acceder a cierta verdad de sus inclinaciones afectivas ${ }^{11}$, comunica dos ocurrencias fundamentales: llevar un diario es como hacer una ikebana -retirarse discretamente del curso del mundo para componer una obra investida con la potencia de lo frágil- y los diarios de artista son libros de autoayuda. Ikebana política es un memorial de los ejercicios cumplidos por la diarista y un cuaderno de ejercitaciones que abunda en la enunciación de reglas, consignas y principios para orientar los aprendizajes y las prácticas en un sentido ético. "Yo pienso: ¿quién no quisiera escribir libros de autoayuda?" (p. 101). Podría pasar por una provocación (los libros de autoayuda tienen mala prensa, por buenas

\footnotetext{
$8 \quad$ La inteligencia compositiva de la archivista quiso que lkebana política se interrumpiera después de la transcripción del "Diario de Bispo", un rosario de asombros y revelaciones, para que el lector fantasee un recomienzo que solo podría cumplirse bajo el signo barthesiano de la "Vita Nova".

$9 \quad$ "La naturaleza política y económica del dibujo es de restricción y sencillez" (p. 63).

10 Debo esta erudición de segunda mano sobre el arte de la ikebana, a un servicial artículo de Wikipedia: https://es.wikipedia. org/wiki/ikebana [última visita: 23 de mayo de 2017].

11 Ver Foucault, 2006, p. 33 y ss.
} 
razones), pero es otro gesto irónico, un modo necesariamente equívoco de aproximarse a la ambigüedad de lo verdadero. Tomemos un ejemplo, el ejercicio de hacer listas, tan frecuente en los diarios o las agendas. Del Río recuerda que, en 1990, y hasta 2001, escribió una lista de oraciones consignando lo que usaba en su trabajo para poder ver y comprender qué estaba haciendo, una lista destinada al conocimiento y el cuidado de la orientación que habían tomado y podrían tomar sus búsquedas artísticas. La transcribe en la página 17 de Ikebana politi$c a$, cada oración comienza con "Uso...", y lo que queda es un inventario abigarrado de recursos extremadamente heterogéneos (la ficción, platos, el boxeo, fieltro, mapas, el archivo policial, floreros, jabones, latas de coca-cola...).
En tres ítems se repite una misma idea: tal cosa la usa porque le recuerda algo esencial de la humana condición, porque le permite revivir de qué estamos hechos, qué nos impulsa o tiende a inmovilizarnos. Usa animales porque en su mudez y su andar le recuerdan "nuestra protohistoria" (también podría haber dicho que los usa para no olvidar que la intimidad, el secreto al que da forma la escritura del diario, "es la animalidad específicamente humana") ${ }^{12}$.

Usa el gesto de dormir, que nos entrena para la muerte, lo mismo que la noción de enfermedad leve, porque nos recuerdan que la vida solo se siente cuando está amenazada y que ser es sobrevivir. Prolongando el impulso, la lista podría haber incluido el uso de listas de elementos heterogéneos, porque nos recuer- dan que todo ordenamiento es circunstancial y provisorio. Las listas de Ikebana política -hay muchas-son del tipo de las que nos permiten entrever un movimiento imperceptible de variación continua, ritmos, a través del acto de identificar un rasgo, un nombre, o un modo de existencia. Son eficaces en términos de autoayuda porque el budismo pop no aspira al control de sí mismo, sino al aprendizaje metódico, ascético, de la capacidad de perderse en lo indeterminado para poder mutar. No hay que forzar a la Gracia -indica la “maestra Ligereza" (p. 20). Hay que trabajar con inocencia en la investigación y la depuración de sí mismo, desprenderse, allí donde se pueda, de los ideales Mayores, para abrirse a la posibilidad de discretas -a veces desconcertantes, a veces risueñas- metamorfosis.

\section{Referencias}

Bourriaud, N. (2009). Formas de vida. El arte moderno y la invención de sí. (C. Rivera Parra, trad.). Murcia: Cendeac.

Del Río, C. (2016). Ikebana política: Libretas y cuadernos (2005-2015). Rosario: Iván Rosado.

Foucault, M. (2006). La hermenéutica del sujeto. Curso en el Collège de France (1981-1982). (H. Pons, trad.). Buenos Aires: Fondo de Cultura Económica.

Hernández Peñaloza, A.A. (enero-junio de 2016). El diario de un escritor en Encuentro en Saint-Nazaire de Ricardo Piglia. La Palabra, (28), 75-90.

12 Pardo, 1996, p. 42. 
Márai, S. (2008). Diarios 1984-1989. (E. Cserhati \& A.M. Fuentes Gaviño, trad.). Barcelona: Salamandra.

Molloy, S. (1996). Acto de presencia. México: Fondo de Cultura Económica.

González Otero, A. (julio-diciembre de 2016). Definiciones y aproximaciones teóricas al género de la literatura de viajes. La Palabra, (29), 65-78.

Pardo, J. L. (1996). La intimidad. Valencia: Pre-Textos.

Rancière, J. (2014). El método de la igualdad. Conversaciones con Laurent Jean Pierre y Dork Zabunyan. (P. Betesh, trad.). Buenos Aires: Nueva Visión.

Rosa, N. (1990). El arte del olvido. Buenos Aires: Puntosur.

Souza, E. M. (enero-junio de 2017). Autoficção e sobrevivência. La Palabra, (30).

Surghi, C. E. (enero-junio de 2017). Kierkegaard: literatura, filosofía, vida. La Palabra, (30).

Woolf, V. (1954). Diario de una escritora. (M. de José Coco Ferraris, trad.). Buenos Aires: Sur. 